\title{
脳卒中における細動脈硬化の生理機能的指標の検討
}

\author{
土井尻 遼介 ${ }^{1 ｝ \text {, 斎藤 こずえ }{ }^{1 ｝ \text {, 内山 真一郎 }{ }^{2)} \text {, 北川 一夫 }{ }^{3 ｝ \text {, 竹川 英宏 }{ }^{5)} \text {, 田所 靖啓 }{ }^{3)} \text {, }$ \\ 堤 由紀子 ${ }^{2)}$, 藤代 健太郎 $^{4)}$, 松本 昌泰 ${ }^{6,7)}$, 山村 修 $^{8)}$, 長束 一行 ${ }^{1)}$ \\ 1) 国立循環器病研究センター脳神経内科 \\ 2) 東京女子医科大学神経內科 \\ 3) 大阪大学大学院医学系研究科神経内科学 \\ 4) 東邦大学医学部教育開発室 \\ 5) 獨協医科大学神経内科 \\ 6) 広島大学大学院脳神経内科学 \\ 7) 堺市立総合医療センター \\ 8) 福井大学医学部付属病院脳神経内科
}

\section{Physiological parameters of cerebral small-vessel disease}

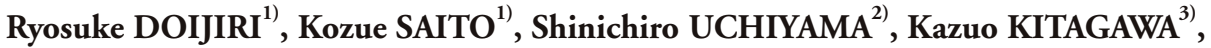 \\ Hidehiro TAKEKAWA ${ }^{5)}$, Yasuhiro TADOKORO ${ }^{3)}$, Yukiko TSUTSUMI ${ }^{2)}$, Kentaro FUJISHIRO ${ }^{4)}$, \\ Masayasu MATSUMOTO ${ }^{6,7)}$, Osamu YAMAMURA ${ }^{8)}$, Kazuyuki NAGATSUKA ${ }^{1)}$ \\ 1) Division of Neurology, National Cerebral and Cardiovascular Center \\ 2) Department of Neurology, Tokyo Women's Medical University School of Medicine \\ 3) Stroke Division, Department of Neurology, Osaka University Graduate School of Medicine \\ 4) Office of Educational Development, Faculty of Medicine Toho University \\ 5) Department of Neurology, Dokkyo Medical University \\ 6) Department of Clinical Neuroscience and Therapeutics, Hiroshima University Graduate School of Biomedical and Health Sciences \\ 7) Sakai City Medical Center \\ 8) Department of Neurology, Faculty of Medical Science, University of Fukui Hospital
}

Objective: Lacunar infarction and intracerebral hemorrhage (ICH) have common characteristics of cerebral small-vessel disease (CSVD) although they are classified as different stroke subtypes. Previous studies showed a positive correlation of CSVD with physiological parameters such as pulse wave velocity (PWV) or with radiographical findings such as leukoaraiosis; however, the role of these parameters remains controversial. Therefore, we assessed whether there is a relationship between stroke subtypes and these potential CSVD-related parameters.

Methods: In a multicenter, retrospective study from 8 hospitals, we enrolled 874 patients with a history of cerebral infarction or ICH who underwent both carotid ultrasound and MRI examination between June 2008 and May 2010. We evaluated the values of PWV, ultrasonographic parameters and MRI findings, and compared them between the stroke subtypes.

Results: Of patients, 331 (38\%) were classified into the large artery atherosclerosis (LAA) group, 387 (44\%) into the small vessel occlusion (SVO) group, and 156 (18\%) into the ICH group. Lower max intima media thickness (IMT) and lower plaque score, and higher PWV were shown in SVO and ICH groups than those in LAA groups. Higher pulsatility index (PI) of common carotid artery (CCA) in SVO group, higher PI of ICA and higher prevalence of cerebral micro-bleeds (CMB) in ICH group were also shown than those in LAA group. After adjustment for vascular risk factors, the following parameters in both SVO and ICH groups were significantly different from those in the LAA group: lower max IMT, lower plaque score, higher periventricular hyperintensity (PVH) grade, and higher prevalence of CMB. PIs of CCA and internal carotid artery (ICA) were higher in ICH group than those in LAA group.

Conclusions: The similar trends of some physiological and radiographical parameters were shown in ICH and SVO group compared with LAA group, which reflected the underlying pathophysiology of CSVD.

Keywords: arteriolosclerosis, cerebral small-vessel disease, stroke, parameters, pulsatility index

(Received January10, 2019; Accepted January 31, 2019)

Reprint request

土井尻遼介：干 020-0066 岩手県盛岡市上田 1-4-1 岩手県立中央病院神経内科

Ryosuke DOIJIRI: Department of Neurology, Iwate Prefectural Central Hospital, 1-4-1, Ueda, Morioka 020-0066, Japan

E-mail: doijirir@gmail.com, Tel: +81-19-653-1151, Fax: +81-19-653-8919 


\section{はじめに}

脳卒中の基盤となる動脈硬化は，主として熪状硬化と 細動脈硬化に大別される。濑状硬化の有無, 程度につい ては画像検査法の進歩により, 早期から詳細な診断が可 能であるが, 細動脈硬化については，血管径が細いため 従来の画像診断技術では評価が困難である。日本をはじ めとするアジア諸国の脳卒中病型はラクナ梗塞や脳出血 が欧米よりも頻度が高く ${ }^{1)}$, 診断や治療法を確立してい く必要がある。病理学的にはラクナ梗塞では特に $200 \mu \mathrm{m}$ 以下の穿通枝動脈で fibrinoid necrosis, lipohyalinosis, 高血圧性脳内出血では microaneurysm と呼ばれ る特異的な変性像を呈することが知られており, ラクナ 梗塞と脳出血は細動脈に血管病変を生じる点で類似した 病態と考えられている ${ }^{2)}$. 碄状硬化の生理機能的なパラ メータとして, 頸動脈内中膜複合体厚（intima-media thickness：IMT)，プラークスコア (plaque score：PS) などの指標が広く知られているが ${ }^{3)}$, 細動脈硬化の程度 を評価する指標としての報告は少なく，脳卒中病型間で の検討は明確になされていない，そこでわれわれは脳卒 中病型間で生理機能検査, 画像検査を検討し, 脳卒中に おける細動脈硬化と関連する生理学的指標を検討した。

\section{対象・方法}

2008 年 6 月から 2010 年 5 月まで全国 8 施設での頸 部エコー検査, 磁気共鳴画像法 (magnetic resonance imaging：MRI）を行った大血管アテローム硬化（large artery atherosclerosis：LAA），小血管閉塞（small vessel occlusion：SVO), 高血圧性脳内出血（intracerebral hemorrhage：ICH）の既往のある 874 例（年齢 $70 \pm$ 10 歳, 男性 67\%）を対象に後乃向きに検討した。脳梗 塞の病型分類は Trial of Org 10172 in Acute Stroke Treatment（TOAST） 分類 ${ }^{4}$ を使用した。脳卒中危険因子で ある高血圧，脂質異常症，糖尿病，body mass index，喫 煙, 飲酒の有無を調查した。生理学的検査としては, 頸 部エコー検查, 血圧脈波検查のデータを解析した，頸部 エコー検查は全例仰臥位で施行し, maximum intimamedia thickness (max-IMT) は総頸動脈 (common carotid artery：CCA）の far wall 側で最大の IMTを計 測した. PS は頸動脈を総頸動脈 2 力所, 分岐部, 内頸 動脈の 4 分割にし，その各部位で認められるプラーク の最大值を総和したものとした ${ }^{5)}$. 総頸動脈径は, 内中 膜と外膜の境界で外膜間距離を総頸動脈分岐部から $1 \mathrm{~cm}$ 心臟側で拡張末期に計測した。 パルスドプラ法に よる血流速度の測定では, CCA, 内頸動脈（internal carotid artery：ICA）はリニアアレイ探触子（5～ $11 \mathrm{MHz}$ ) で行い, CCA は頸動脈洞から約 $2 \mathrm{~cm}$ 近位部で,
また ICA は CCA 分岐部から約 $3 \mathrm{~cm}$ 遠位部で血管屈曲 部を避けて測定した。なお，計測は日本脳神経超音波学 会のガイドライン ${ }^{6} に$ 準拠し，サンプルボリュームを血 管径の $1 / 2 \sim 2 / 3$ とした．また，パルスドプラ法により CCA，ICA の pulsatility index（PI）を算出した。動脈 スティフネス検査は両側の上腕〜足首間の脈波伝播速度 (brachial-ankle pulse wave velocity：baPWV) を計測し 左右の平均を值とした。 $\max -\mathrm{IMT}, \mathrm{PS}$ は左右平均值を, CCA PI, ICA PI は左右でより低值のもので, 狭窄存在 例では非狭窄側の值を採用した，画像診断の項目として は，頭部 MRI の FLAIR 画像で白質病変である脳室周 囲高信号域（periventricular hyperintensity：PVH）の有 無や程度, T2* 強調画像 (T2* gradient recall echo： GRE）で観察される径 $10 \mathrm{~mm}$ 以下の円形または楕円形 の形態を示す低信号域でとらえられる微小出血 (cerebral microbleeds：CMB）の有無で評価した. PVH の有無や 程度を Fazekas 分類 ${ }^{7)}$ で評価し, grade 2 以上 (中等度以 上）の白質病変 ${ }^{8)}$ を認めた場合に PVH ありと定義した。 統計学的検討は JMP ${ }^{\circledast} 10$ Statistical Software（SAS Institute, Cary, NC) を使用し, $t$ 検定, $\chi^{2}$ 検定, ロジスティッ ク回帰分析（変数は，ステップワイズ変数選択法を用い て動脈硬化危険因子から選択した）を行い, $p<0.05$ を統計的に有意と判断した。

な㧍本研究は全国 8 施設の倫理委員会での審査, 承 認を得て実施した。

\section{結果}

病型の内訳は LAA が 331 例 (38\%), SVO が 387 例 (44\%)，ICH が 156 例（18\%）であり，各病型ごとの 臨床的特徴およびパラメータの計測結果を Table 1 にま とめて提示する. LAA 群と比較して SVO 群と ICH 両 群で年齢, 男性比, 脂質異常症, 糖尿病が有意に低值で あり，ICH 群では高血圧の割合が有意に高值であった。 LAA 群ではSVO 群, ICH 群と比較して max-IMT, PS が有意に高值で baPWV は低值であった。ほかにSVO 群では LAA 群と比較して CCA PI $(p=0.03)$ が有意に 低值であった. ICH 群では LAA 群と比較して ICA PI $(p=0.01), \mathrm{CMB}$ 陽性率 $(p<0.01)$ が有意に高值であっ た。多重ロジスティック回帰分析では LAA 群と比較し て SVO 群では max-IMT〔odds ratio（OR）：0.93，95\% confidence interval $(95 \% \mathrm{CI}): 0.90 \sim 0.96, p<0.01$ ], PS（OR : $0.90,95 \%$ CI : $0.88 \sim 0.93, p<0.01)$ が 有意に低く，中等度以上の白質病変 $(\mathrm{OR}: 1.55,95 \%$ $\mathrm{CI}: 1.11 \sim 2.18, p=0.01$ ), CMB 陽性率（OR: 1.51, 95\% CI : $1.00 〜 2.28, p=0.04)$ が有意に高值であった. ICA PI 值は有意ではなかったものの, 高い傾向を認め た(OR : 1.06, 95\% CI : 0.99 1.14, $p=0.05)$ (Fig.1). 
Table 1 Baseline characteristics

\begin{tabular}{lccc}
\hline & LAA $(\boldsymbol{n}=\mathbf{3 3 1})$ & SVO $(\boldsymbol{n}=\mathbf{3 8 7})$ & ICH $(\boldsymbol{n}=\mathbf{1 5 6})$ \\
\hline Age $($ years old) & $71.5 \pm 0.6$ & $69.8 \pm 0.5^{\dagger}$ & $67.9 \pm 0.8^{\dagger}$ \\
Male, $n(\%)$ & $248(75)$ & $253(66)^{\dagger}$ & $91(58)^{\dagger}$ \\
BMI $\left(\mathrm{kg} / \mathrm{m}^{2}\right)$ & $22.9 \pm 0.25$ & $22.9 \pm 0.24$ & $22.6 \pm 0.35$ \\
Hypertension, $n(\%)$ & $257(78)$ & $278(72)$ & $143(92)^{\dagger}$ \\
Dyslipidemia, $n(\%)$ & $205(62)$ & $187(48)^{\dagger}$ & $49(31)^{\dagger}$ \\
Diabetes $(\%)$ & $130(39)$ & $116(30)^{\dagger}$ & $33(21)^{\dagger}$ \\
Surplus alcohol use (\%) & $127(47)$ & $99(43)$ & $56(38)$ \\
Current smoking (\%) & $74(27)$ & $67(28)$ & $26(19)$ \\
Max-IMT (mm) & $2.04 \pm 1.03$ & $1.52 \pm 0.74^{\dagger}$ & $1.24 \pm 0.61^{\dagger}$ \\
PS & $6.97 \pm 6.35$ & $3.92 \pm 4.41^{\dagger}$ & $3.23 \pm 3.86^{\dagger}$ \\
CCA PI & $1.59 \pm 0.34$ & $1.55 \pm 0.38^{\dagger}$ & $1.69 \pm 0.48$ \\
ICA PI & $1.03 \pm 0.24$ & $1.05 \pm 0.24$ & $1.14 \pm 0.35^{\dagger}$ \\
CCA external diameter (mm) & $7.74 \pm 1.16$ & $7.63 \pm 1.11$ & $7.53 \pm 1.11$ \\
baPWV (m/s) & $17.3 \pm 3.7$ & $19.5 \pm 4.1^{\dagger}$ & $20.0 \pm 4.7^{\dagger}$ \\
PVH $\geqq$ grade 2 (\%) & 43 & 50 & 50 \\
Cerebral microbleeds positive (\%) & 36 & 43 & $69^{\dagger}$ \\
\hline
\end{tabular}

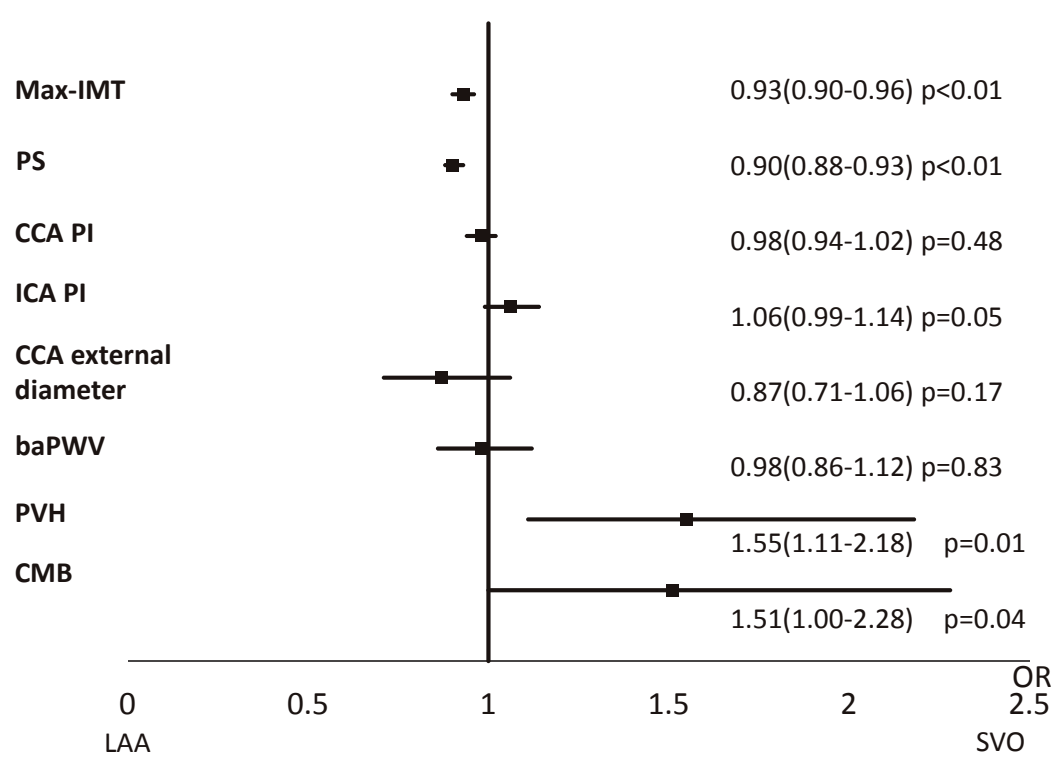

Fig.1 Multivariable adjusted logistic regression LAA vs. SVO

LAA, large artery atherosclerosis; SVO, small vessel occlusion; max-IMT, maximum intima-media thickness; PS, plaque score; CCA PI, common carotid artery pulsatility index; ICA PI, internal carotid artery pulsatility index; CCA external diameter, common carotid artery external diameter; baPWV, brachial-ankle pulse wave velocity; PVH, periventricular hyperintensity; CMB, cerebral microbleeds.

また, ICH 群では max-IMT （OR : 0.89, 95\% CI : 0.86 $\sim 0.92, p<0.01)$, PS (OR : 0.88, 95\% CI : $0.84 \sim$ $0.93, p<0.01)$ が有意に低值であり, CCA PI（OR： $1.09,95 \% \mathrm{CI}: 1.03 \sim 1.16, p<0.01)$, ICA PI (OR : $1.23,95 \% \mathrm{CI}: 1.12 \sim 1.35, p<0.01)$, 中等度以上 の白質病変 $(\mathrm{OR}: 1.90,95 \% \mathrm{CI}: 1.09 \sim 3.33, p=$ 0.02), CMB 陽性率（OR：3.60, 95\% CI : $2.20 \sim 5.88$, $p<0.01$ ) が高值であった（Fig.2）.

\section{考察}

粥状硬化を基盤として発症する脳卒中の病型は LAA が代表的であり, 頸部エコー検査, 頭頸部 MRA, CT- angiography (CTA), 脳血管撮影などで血管狭窄を評価 でき診断可能な病型である。頸部エコー検査での粥状硬 化の指標として非ラクナ梗塞ではラクナ梗塞よりも mean IMT が高值 ${ }^{9)}$, アテローム血栓性では PS が高值 ${ }^{3}$ といった報告がある。一方，脳の細動脈である穿通枝は 直径数十一数百マイクロメートルと血管が細く，一部の 脳血管撮影や高性能の MRA などでかろうじて観察可能 であるが，一般的な MRA や CTA などの画像診断では 直接評価することは困難である，穿通枝動脈の病変であ る細動脈硬化（arteriolosclerosis）は fibrinoid necrosis, lipohyalinosis, microaneurysm といった病理像を呈し ${ }^{1)}$, 閉塞すればラクナ梗塞を，穿破すれば高血圧性脳内出血 


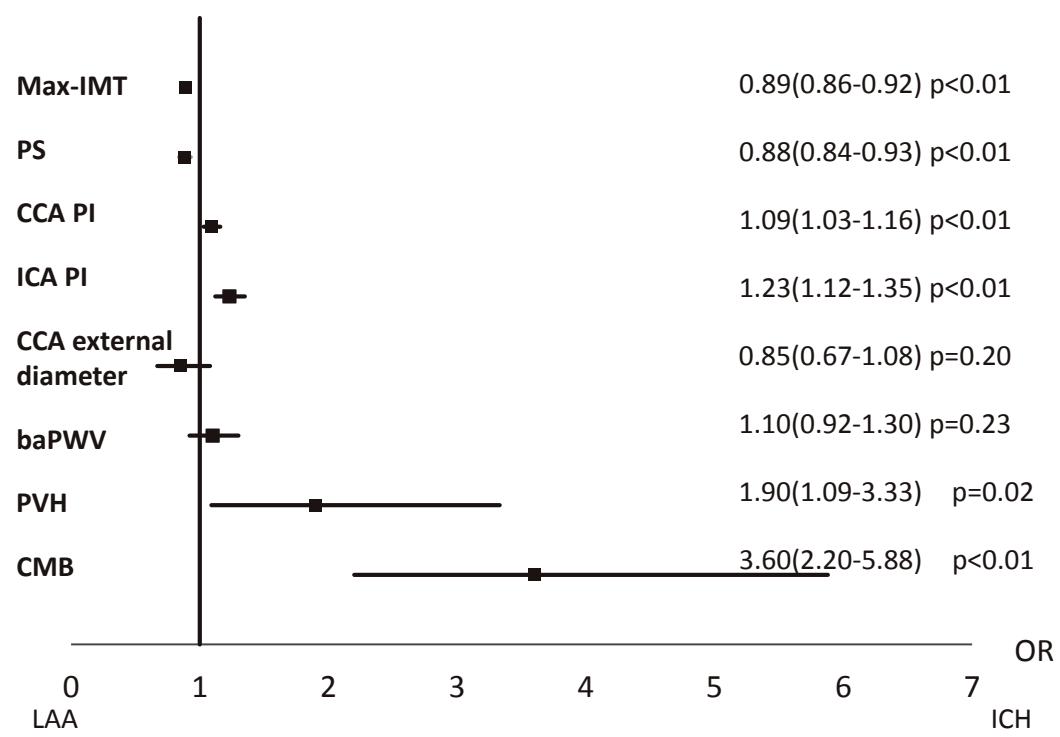

Fig.2 Multivariable adjusted logistic regression LAA vs. ICH

LAA, large artery atherosclerosis; ICH, intracerebral hemorrhage; max-IMT, maximum intima-media thickness; PS, plaque score; CCA PI, common carotid artery pulsatility index; ICA PI, internal carotid artery pulsatility index; CCA external diameter, common carotid artery external diameter; baPWV, brachial-ankle pulse wave velocity; PVH, periventricular hyperintensity; CMB, cerebral microbleeds.

をきたすといわれ ${ }^{10)}$ ，この 2 つの病型には共通の病態 が考えられている.

細動脈硬化を反映するとされ直接脳血流を評価する生 理的パラメータとして, 経頭蓋超音波ドプラ法（transcranial Doppler ultrasonography：TCD）で計測した中 大脳動脈 (middle cerebral artery：MCA）のPI 值を検 討した報告がある。TCDで計測したMCAのPIは lipohyalinosis や microatherosclerosisによる細動脈の狭 小化に伴う血管抵抗の上昇を反映しているといわれてお $り^{11,12)}$ ，MCA PI と細動脈疾患との間には正の相関が認 められている ${ }^{11,13)}$ 。また，中等度以上の白質病変や多発 性ラクナ梗塞例では MCA PI が上昇したという報告 ${ }^{8)}$ もある，TCD は頭蓋内血管を直接評価できる一方，日 本人の側頭骨ウインドウは約 50 ～70\%程度にしか得ら れない ${ }^{14,15)}$ ．特に高齢者では検査が困難なこともあり， われわれは日常診療で行われる頻度が高い頸部エコー検 査で計測可能な CCA PI， ICA PI や baPWV などが簡便 な指標になりうるのではないかと考え, これらのパラ メータを病型別に比較検討した.また, 過去に頸部エコー 検査でラクナ梗塞は非ラクナ梗塞よりも IMT が低值で あり ${ }^{9)}$, PS も低值 ${ }^{3)}$ であると報告されている。本研究 でも多変量解析にて SVO 群と ICH 群で LAA 群より max-IMT, PS が低值であり,さらに ICA PI が高值 (SVO 群 : $p=0.05, \mathrm{ICH}$ 群 $: p<0.01)$ であり，末梢血管抵 抗が高いと考えられた．SVO 群と ICH 群はこれらのパ ラメータに同じ傾向を認め, 両者が細動脈を基礎とした 類似の疾患であるとの考え方で矛盾しない結果であっ た。今回はTCDでの PI 值を計測しておらず直接の関 連について断定はできないが, ICA PI は頭蓋内に流入
する血流を反映しており，やはり細動脈の狭小化に伴う 血管抵抗の上昇を反映しているものと推測された。

baPWV は大血管のスティフネスを評価するものでは あるが，硬化した動脈は脈波の伝播が速くなり，収縮期 に遠位の臓器に血圧波が瞬時に到達して, 最終的に脳の 細動脈に障害が生じるといわれ ${ }^{16)}$, 白質病変例 ${ }^{17)}$, 微 小出血例 ${ }^{18)}$ ， ラクナ梗塞例 ${ }^{19)}$ では baPWV が上昇して いたという報告がある。われわれの今回の検討では，単 変量解析では SVO, ICH 両群で LAA よりも高值であっ たが，動脈硬化危険因子で調整した多変量解析では脳卒 中の病型間で有意差がみられなくなった。その理由とし て, baPWVは動脈硬化危険因子の合併例が非合併例より も高值であり ${ }^{17)}$, 高血圧に起因する動脈硬化進展は器 質的にも動脈の硬さを克進させることから ${ }^{18)}$, baPWV は高血圧などの動脈硬化危険因子に影響され，各病型が 独立した危険因子にはならなかったことが考えられた。

また，細動脈硬化を反映する画像所見として PVH， CMB がある，PVH は慢性虚血性変化を反映し ${ }^{20)}$ ，脳 の髄質動脈の硬化性変化が基盤と考えられている. $\mathrm{CMB}$ は高血圧による細動脈硬化やフィブリノイド壊死 により小血管が障害を受け，無症候性に微小出血をきた したものであり, $\mathrm{CMB}$ の出現頻度はラクナ梗塞, 脳出 血で多いと報告されている ${ }^{21)}$ 。本検討でも SVO, ICH ともに PVHの割合が多く, 微小出血の陽性率が高かっ たことから，これらの画像所見もやはり細動脈硬化を反 映する指標になりうると考えられた。

頸部エコー検査での max-IMT, PS 高值は粥状硬化を 
示唆し，細動脈硬化を基盤とする病態であるSVO, $\mathrm{ICH}$ では両者に共通した生理的指標の変化を示す。こ れらのことから, 生理機能的指標として頸部エコー検査 での ICA PI 值，脳 MRI での PVH，CMB が細動脈硬 化の有用な指標となりうる可能性が示唆された。

\section{謝辞}

本研究は, 厚生労働科学研究費補助金（循環器疾患· 糖尿病等生活習慣病対策総合研究事業）「動脈硬化の多 角的評価による脳卒中個別化治療開発に関する研究」(主 任研究者：長束一行）の援助によってなされた。また， 本研究にご協力いただいた大阪医療センター多賀谷昌史 先生にお礼申し上げます。

本論文の要旨は, 第 30 回日本脳神経超音波学会総会 （2011 年 7 月，長崎）において発表した。

利益相反：すべての著者に，本論文に関して開示すべ き利益相反状態はない。

\section{-文献}

1) Fisher CM. The arterial lesions underlying lacunes. Acta Neuropathol 1969; 12: 1-15.

2) Kato $H$, Izumiyama $M$, Izumiyama $K$, et al.: Silent cerebral microbleeds on $\mathrm{T} 2{ }^{*}$-weighted MRI: correlation with stroke subtype, stroke recurrence, and leukoaraiosis. Stroke 2002; 33: 1536-1540.

3) Nagai Y, Kitagawa K, Sakaguchi M, et al.: Significance of earlier carotid atherosclerosis for stroke subtypes. Stroke 2001; 32: 1780-1785.

4) Adams HP Jr, Bendixen BH, Kappelle LJ, et al.: Classification of subtype of acute ischemic stroke. Definitions for use in a multicenter clinical trial. TOAST. Trial of Org 10172 in Acute Stroke Treatment. Stroke 1993; 24: 35-41.

5) Handa $N$, Matsumoto $M$, Maeda $H$, et al: Ultrasonic evaluation of early carotid atherosclerosis. Stroke 1990; 21: 1567-1572.

6) 頸部血管超音波検査ガイドライン. Neurosonology 2006；19: 49-69.

7) Fazekas F, Chawluk JB, Alavi A, et al.: MR signal abnormalities at $1.5 \mathrm{~T}$ in Alzheimer's dementia and normal aging. AJR Am J Roentgenol 1987; 149: 351-356.

8) Kim DH, Choi JH, Moon JS, et al.: Association between the severity of cerebral small vessel disease, pulsatility of cerebral arteries, and brachial ankle pulse wave velocity in patients with lacunar infarction. Eur Neurol 2010; 64: 247-252.

9) Cupini LM, Pasqualetti P, Diomedi M, et al.: Carotid artery intima-media thickness and lacunar versus nonlacunar infarcts. Stroke 2002; 33: 689-694.

10) Greenberg SM. Small vessels, big problems. N Engl J Med 2006; 354: 1451-1453.

11) Kidwell CS, el-Saden S, Livshits Z, et al.: Transcranial Doppler pulsatility indices as a measure of diffuse small-vessel disease. J Neuroimaging 2001; 11: 229-235.

12) Chamorro A, Pujol J, Saiz A, et al.: Periventricular white matter lucencies in patients with lacunar stroke. A marker of too high or too low blood pressure? Arch Neurol 1997; 54: 1284-1288.

13) Lee KY, Sohn YH, Baik JS, et al.: Arterial pulsatility as an index of cerebral microangiopathy in diabetes. Stroke 2000; 31: 11111115.

14) Yagita $Y$, Etani $H$, Handa $N$, et al.: Effect of transcranial Doppler intensity on successful recording in Japanese patients. Ultrasound Med Biol 1996; 22: 701-705.

15) Itoh $T$, Matsumoto $M$, Handa $N$, et al.: Rate of successful recording of blood flow signals in the middle cerebral artery using transcranial Doppler sonography. Stroke 1993; 24: $1192-$ 1195.

16) Izzo JL Jr: Arterial stiffness and the systolic hypertension syndrome. Curr Opin Cardiol 2004; 19: 341-352.

17) Lehmann ED, Hopkins KD, Rawesh A, et al.: Relation between number of cardiovascular risk factors/events and noninvasive Doppler ultrasound assessments of aortic compliance. Hypertension 1998; 32: 565-569.

18) Stewart AD, Jiang B, Millasseau SC, et al.: Acute reduction of blood pressure by nitroglycerin does not normalize large artery stiffness in essential hypertension. Hypertension 2006; 48: 404410.

19) Henskens LH, Kroon AA, van Oostenbrugge RJ, et al.: Increased aortic pulse wave velocity is associated with silent cerebral small-vessel disease in hypertensive patients. Hypertension 2008; 52: 1120-1126.

20) Jones DK, Lythgoe D, Horsfield MA, et al.: Characterization of white matter damage in ischemic leukoaraiosis with diffusion tensor MRI. Stroke 1999; 30: 393-397.

21) Cordonnier C, Al-Shahi Salman R, Wardlaw J: Spontaneous brain microbleeds: Systematic review, subgroup analyses and standards for study design and reporting. Brain 2007; 130: 1988-2003. 